Article

\title{
Characterization of NS5A and NS5B Resistance-Associated Substitutions from Genotype 1 Hepatitis C Virus Infected Patients in a Portuguese Cohort
}

\author{
Ruben Brandão ${ }^{1, *(D)}$, Rute Marcelino ${ }^{2}$ (D), Fátima Gonçalves ${ }^{1}$, Isabel Diogo ${ }^{1}$, Ana Carvalho ${ }^{1}$, \\ Joaquim Cabanas ${ }^{1}$, Inês Costa ${ }^{1}$, Pedro Brogueira ${ }^{3}$, Fernando Ventura ${ }^{3}$, Ana Miranda ${ }^{3}$, \\ Kamal Mansinho ${ }^{3}$ and Perpétua Gomes ${ }^{1,4}$ (iD) \\ 1 Molecular Biology Laboratory, LMCBM, SPC, HEM-Centro Hospitalar Lisboa Ocidental, 1349-019 Lisboa, \\ Portugal; mfmgoncalves@chlo.min-saude.pt (F.G.); ifmadeira@chlo.min-saude.pt (I.D.); \\ pkarvalho@iol.pt (A.C.); jcabanas65@gmail.com (J.C.); icosta@chlo.min-saude.pt (I.C.); \\ gomes.perpetua@gmail.com (P.G.) \\ 2 Global Health and Tropical Medicine (GHTM), Unit of Medical Microbiology, Instituto de Higiene e \\ Medicina Tropical (IHMT), Universidade NOVA de Lisboa (UNL), 1349-008 Lisboa, Portugal; \\ rute.marcelino@ihmt.unl.pt \\ 3 Serviço de Doenças Infeciosas, HEM-Centro Hospitalar Lisboa Ocidental, 1349-019 Lisboa, Portugal; \\ pbrogueira@gmail.com (P.B.); venturafa@gmail.com (F.V.); anacbcm@gmail.com (A.M.); \\ mansinho.k@gmail.com (K.M.) \\ 4 Centro de Investigação Interdisciplinar Egas Moniz, CiiEM, ISCSEM, 2829-511 Almada, Portugal \\ * Correspondence: ruben8brandao@gmail.com; Tel.: +351-935-150-763
}

Received: 11 April 2018; Accepted: 22 April 2018; Published: 26 April 2018

check for updates

\begin{abstract}
This study is focused on the prevalent NS5 coding region resistance-associated substitutions (RASs) in DAA-naive genotype (GT)1 HCV-infected patients and their potential impact on success rates. Plasma RNA from $81 \mathrm{GT1} \mathrm{HCV}$-infected patients was extracted prior to an in-house nested RT-PCR of the NS5 coding region, which is followed by Sanger population sequencing. NS5A RASs were present in $28.4 \%(23 / 81)$ of all GT1-infected patients with $9.9 \%(8 / 81)$ having the $\mathrm{Y} 93 \mathrm{C} / \mathrm{H}$ mutation. NS5B RASs showed a prevalence of $14.8 \%(12 / 81)$ and were only detected in GT1b. Overall $38.3 \%(31 / 81)$ of all GT1 HCV-infected patients presented baseline RASs. The obtained data supports the usefulness of resistance testing prior to treatment since a statistically significant association was found between treatment failure and the baseline presence of specific NS5 RASs known as $\mathrm{Y} 93 \mathrm{C} / \mathrm{H}$ $(p=0.04)$.
\end{abstract}

Keywords: hepatitis C virus; direct-acting antivirals; resistance-associated substitutions; NS5A; NS5B

\section{Introduction}

The hepatitis $\mathrm{C}$ virus (HCV) is considered to be the second leading cause of hepatocellular carcinoma (HCC) and further co-morbidities such as cirrhosis and other chronic liver diseases. Data from 2017 on the Global Burden of Disease Study (GBD) estimate that about 158 million people are seropositive for HCV (see Figure 1) [1]. Moreover, the number of HCV-associated mortalities has also seen a decrease over the years to about 489,000 reported deaths of which more than 159,500 were related to liver cancer due to $\mathrm{HCV}$ [2]. 


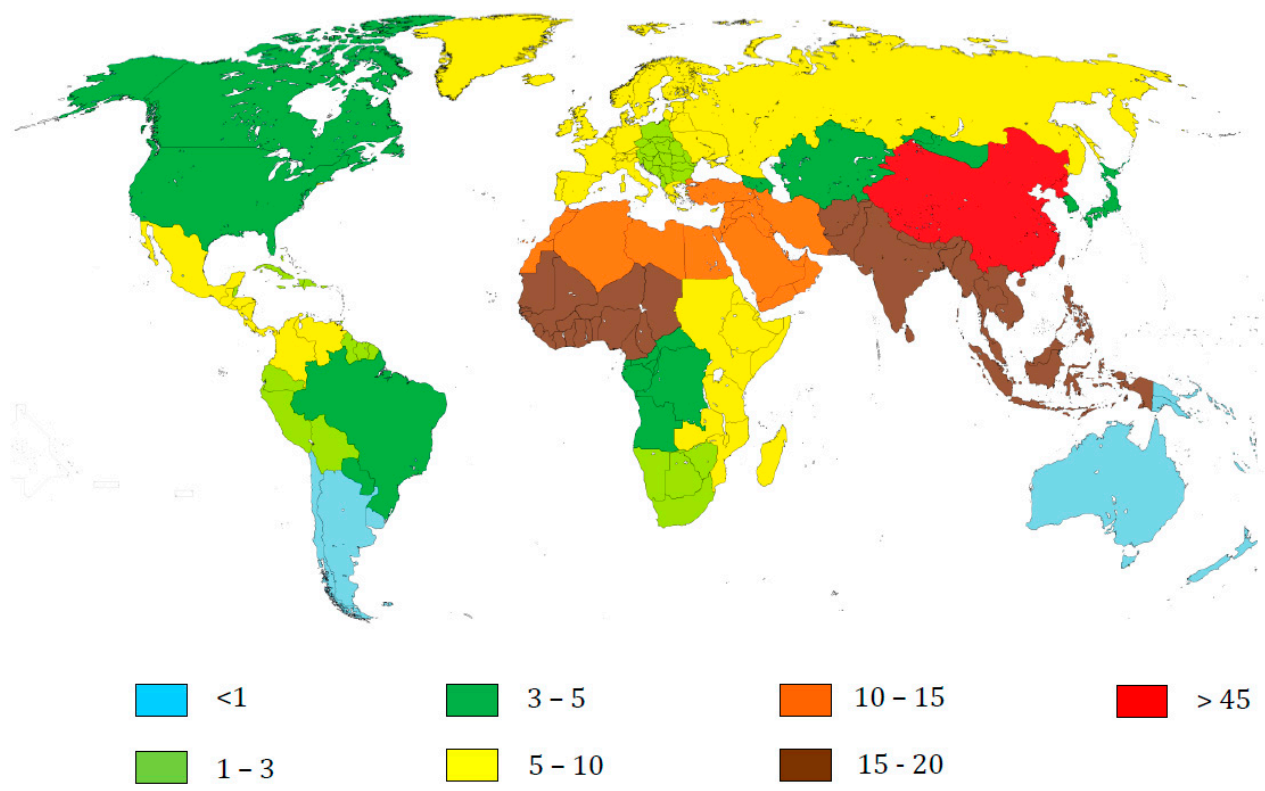

Figure 1. Worldwide estimated people with anti-HCV antibodies in 2016 (in millions) in 21 GBD regions. Data obtained from References [1,3].

$\mathrm{HCV}$ is highly diversified and demonstrates a geographic distribution since it is currently divided into seven genotypes and more than 80 known subtypes of which the first genotype is the most prevalent. The first genotype globally accounts for 83.4 million (46.2\%) of all HCV infections while HCV GT3 constitutes the second most common with 54.3 million (30.1\%) cases worldwide [4].

Since 2014, IFN-free regimens constitute the best treatment options in chronic Hepatitis C infection for treatment-naive (TN) and treatment-experienced (TE) patients with compensated or decompensated liver disease as a result of the ease of use through all-oral DAAs, increased tolerability, and the dramatic increase in viral suppression demonstrating SVR rates superior to 90\% [5-20]. Current NS5A inhibitors such as ledipasvir (LDV) and velpatasvir (VEL) exhibit a high genetic barrier to resistance when compared to the first generation precedents. However, this is not as high as the nucleoside inhibitors (NIs) of the NS5B polymerase currently known as sofosbuvir [21]. However, DAAs regimens are still not $100 \%$ effective due to low adherence to treatment as well as due to the presence of baseline RASs, which show that only high risk NS5A and NS5B RASs appear to have an impact on the response to treatment when exposing an HCV-infected patient to an IFN-free therapy based in SOF/LDV $\pm \mathrm{RBV}$ for 12 weeks [22].

Recent studies have described a prevalence of baseline RASs in HCV-infected patients that can range from 1 to $80 \%$ [23], which leads to a decrease in SVR rates between $1 \%$ and $50 \%$ [23]. NS5A constitutes the most important genomic region considered for the screening of associated clinically relevant RASs since it displays the highest number of mutations in GT1 HCV while regimens based on NS5B polymerase inhibitors, particularly NIs, tend to exhibit a low prevalence of baseline RASs [24] and the S282T mutation, although very relevant in therapeutic failures after a treatment with NIs, is rarely detected at baseline [25]. Furthermore, the ION clinical trials [15-17] have shown that reduced rates of SVR observed after a regimen of SOF + LDV for 12 weeks in patients infected with GT1 HCV were essentially associated with the presence of baseline NS5A RAS, which conferred an in vitro high fold resistance ( $>100)$ to ledipasvir [26].

Our main goal was to study the profile of NS5 coding region RASs in DAA-naive genotype 1 among HCV-infected patients. Additionally, three separate hypotheses were tested to ascertain an association between treatment failure and: (a) the non-discriminatory presence of baseline NS5 RASs, (b) the baseline presence of NS5A, NS5B and / or NS5A + NS5B class RASs, and (c) the baseline presence of specific NS5 RASs. 


\section{Materials and Methods}

\subsection{Samples}

This study was approved on 6 September 2017 by the Ethical Committee for Health of Centro Hospitalar de Lisboa Ocidental (CHLO) with the RNEC Registry Number: 20170700050.

A group of 81 clinical samples of plasma from DAA-naïve GT1a and GT1b-infected patients selected to initiate treatment with DAAs between 2015 and 2017 were analyzed for baseline NS5 RASs profiling. The viral load had been previously determined using the Quantitative/Qualitative COBAS ${ }^{\circledR}$ AmpliPrep/TaqMan ${ }^{\circledR}$ HCV Test v2.0 from Roche Molecular Diagnostics (Basel, Switzerland). The HCV genotype had been previously determined using the VERSANT ${ }^{\circledR}$ HCV Genotype 2.0 Assay Line Probe Assay (LiPA) from INNOGENETICS/Siemens Healthineers (Ghent, Belgium). Twenty-five samples corresponded to GT1b (31\%) while GT1a was the predominant subtype accounting for $56 \mathrm{HCV}$ infected patients (69\%). Moreover, 3 out of the 81 patients had failed a previous treatment with DAAs (4\%), and two patients showed an unknown treatment outcome status ( $2 \%$ ) due to lack of adherence to the associated regimen or loss to follow-up evaluation before the SVR12 visit, which resulted overall in an SVR rate of $94 \%(76 / 81)$ (see Table 1$)$.

Table 1. Demographic baseline characteristics of the HCV-infected patients and treatment outcomes.

\begin{tabular}{|c|c|}
\hline \multicolumn{2}{|c|}{ DAA-Naive HCV Infected Patients $(n=81)$} \\
\hline Mean age, years (range) & $49(23-81)$ \\
\hline Male sex, $n(\%)$ & $63(78 \%)$ \\
\hline \multicolumn{2}{|l|}{ Genotype, $n(\%)$} \\
\hline GT1a & $56(69 \%)$ \\
\hline GT1b & $25(31 \%)$ \\
\hline \multicolumn{2}{|l|}{ Monoinfection and co-infection profile, $n(\%)$} \\
\hline HCV monoinfected & $26(32 \%)$ \\
\hline $\mathrm{HIV} / \mathrm{HCV}$ & $42(52 \%)$ \\
\hline $\mathrm{HCV} / \mathrm{HBV}$ & $4(5 \%)$ \\
\hline $\mathrm{HIV} / \mathrm{HCV} / \mathrm{HBV}$ & $9(11 \%)$ \\
\hline Mean $\log _{10}$ HCV RNA, IU / mL (range) & $6.22(4.8-7.4)$ \\
\hline \multicolumn{2}{|l|}{ HCV RNA, IU/mL, $n(\%)$} \\
\hline$<2$ million & $43(53 \%)$ \\
\hline 2-6 million & $30(37 \%)$ \\
\hline$>6$ million & $8(10 \%)$ \\
\hline \multicolumn{2}{|l|}{ IL28B, $n(\%)$} \\
\hline $\mathrm{CC}$ & $23(28 \%)$ \\
\hline $\mathrm{CT}$ & $47(58 \%)$ \\
\hline TT & $6(8 \%)$ \\
\hline Unknown & $5(6 \%)$ \\
\hline \multicolumn{2}{|l|}{ Outcome after treatment with DAAs, $n(\%)$} \\
\hline SVR12 or SVR24 & $76(94 \%)$ \\
\hline Treatment failure & $3(4 \%)$ \\
\hline Unknown & $2(2 \%)$ \\
\hline
\end{tabular}

\subsection{HCV RNA Extraction}

$\mathrm{HCV}$ nucleic acids were extracted from $500 \mu \mathrm{L}$ of plasma previously conserved at $-80{ }^{\circ} \mathrm{C}$, which ultimately eluted $45 \mu \mathrm{L}$ of RNA product using the bioMérieux's automated NucliSENS ${ }^{\circledR}$ EasyMAG ${ }^{\circledR}$ system v2.0 (with silica, Boxtel, The Netherlands), according to the manufacturer's protocol. 


\subsection{PCR and Sequencing Primers Design}

In order to cover the NS5A and NS5B coding regions, each amplification reaction used two primers including one forward primer and one reverse, which encompasses a length of approximately $4800 \mathrm{bp}$ and $3700 \mathrm{bp}$ for the RT-PCR (outer PCR) and nested PCR (inner PCR), respectively (see Table S1). A total set of 10 primers (Table S1) of which two were subtype specific were selected to cover the NS5 coding region of GT1 HCV. However, since the $3^{\prime}$-end of the NS5B gene is a poly-U (U/C) region highly composed of hairpins and secondary structures that obstruct the annealing process, the associated FW6 sequencing primer was unable to completely hybridize during the sequencing reactions. Three important amino acid positions (A553, G554, and S556) associated with resistance to dasabuvir were consequently left uncovered. Primers were synthesized by Thermo Fisher Scientific (Waltham, MA, USA) and TIB MOLBIOL (Berlin, Germany).

\section{4. cDNA Synthesis and Nested-PCR}

HCV RNA was reverse transcribed using the OneStep RT-PCR Kit from QIAGEN (Hilden, Germany) and this first round of amplification (outer PCR) was performed under the following final conditions: OneStep RT-PCR Buffer $(1 \times), 2.5 \mu \mathrm{L}$ of OneStep RT-PCR Enzyme Mix, dNTPs Mix $(400 \mu \mathrm{M}$ each), $0.5 \mu \mathrm{M}$ sense primer FW1, $0.5 \mu \mathrm{M}$ anti-sense primer RV1, $10 \mathrm{U} /$ reaction of protector RNase inhibitor, $10 \mu \mathrm{L}$ of template RNA, and RNase-Free water to make up a final reaction volume of $50 \mu \mathrm{L}$. Cycling conditions were as follows: a reverse transcription step at $45^{\circ} \mathrm{C}$ for $30 \mathrm{~min}$, a HotStarTaq polymerase activation step at $95^{\circ} \mathrm{C}$ for $15 \mathrm{~min}$ to initiate PCR, a touchdown PCR step of 16 cycles of $10 \mathrm{~s}$ at $94{ }^{\circ} \mathrm{C}$ (denaturation step), $45 \mathrm{~s}$ at $63{ }^{\circ} \mathrm{C}$ with $-1{ }^{\circ} \mathrm{C} /$ cycle (annealing step), and $5 \mathrm{~min}$ at $68^{\circ} \mathrm{C}$ (extension step), a final PCR step of 30 cycles of $10 \mathrm{~s}$ at $94{ }^{\circ} \mathrm{C}, 45 \mathrm{~s}$ at $48^{\circ} \mathrm{C}$, and $5 \mathrm{~min}$ at $68^{\circ} \mathrm{C}$ with a time increment of $+3 \mathrm{~s} / \mathrm{cycle}$, and a final elongation step of $10 \mathrm{~min}$ at $68^{\circ} \mathrm{C}$. The reaction was then cooled down to $4{ }^{\circ} \mathrm{C}$ and RT-PCR products were stored at $-20{ }^{\circ} \mathrm{C}$ or immediately used in the nested PCR step.

Two microliters of the RT-PCR reaction product were amplified in a second in-house nested PCR (inner PCR) divided in two mixes, which was as recommended by the Expand High Fidelity PCR System Kit (Roche), under the following conditions: Mix 1 (dNTPs mix (200 $\mu \mathrm{M}$ each), $0.3 \mu \mathrm{M}$ sense primer FW2, $0.3 \mu \mathrm{M}$ anti-sense primer RV2, and RNase-Free water to make up a mix volume of $23 \mu \mathrm{L}$ ) and Mix 2 (Expand High Fidelity Buffer $\left(1 \times\right.$ ) without $\mathrm{MgCl}_{2}, 0.4 \% \mathrm{DMSO}, 3 \mathrm{mM} \mathrm{MgCl} 2,3 \mathrm{U} /$ reaction of Expand High Fidelity Enzyme mix, and RNase-Free water to make up a mix volume of $25 \mu \mathrm{L}$ ). Lastly, $2 \mu \mathrm{L}$ of template cDNA were mixed with $23 \mu \mathrm{L}$ of Mix 1, which is followed by adding $25 \mu \mathrm{L}$ of Mix 2 to make a final reaction volume of $50 \mu \mathrm{L}$ for each sample. Cycling conditions include a denaturation step at $95^{\circ} \mathrm{C}$ for $3 \mathrm{~min}$, a touchdown PCR step of 16 cycles of $15 \mathrm{~s}$ at $94{ }^{\circ} \mathrm{C}, 30 \mathrm{~s}$ at $60^{\circ} \mathrm{C}$ with $-1{ }^{\circ} \mathrm{C} / \mathrm{cycle}$, and $3 \mathrm{~min}$ at $68^{\circ} \mathrm{C}$, a final PCR step of 30 cycles of $15 \mathrm{~s}$ at $94{ }^{\circ} \mathrm{C}, 30 \mathrm{~s}$ at $45^{\circ} \mathrm{C}$, and $3 \mathrm{~min}$ at $68^{\circ} \mathrm{C}$ with a time increment of $+5 \mathrm{~s} /$ cycle, and a final elongation step of $7 \mathrm{~min}$ at $68^{\circ} \mathrm{C}$. The reaction was then cooled down to $4{ }^{\circ} \mathrm{C}$ and nested PCR products were stored at $-20^{\circ} \mathrm{C}$.

Analysis of the PCR products was done via a $1 \%$ agarose gel electrophoresis at $100 \mathrm{~V}$ and obtained nested PCR products were purified using the PCR Cleanup Kit protocol from Abbott Molecular Inc (Des Plaines, IL, USA).

\subsection{Sequencing and Resistance Profile Analysis}

Sanger population sequencing (cut-off value of 15\%) on 3130xl ABI PRISM Genetic Analyzer (ThermoFisher Scientific) was performed for the purified nested-PCR products by using a BigDye ${ }^{\mathrm{TM}}$ Terminator v3.1 Cycle Sequencing kit (Applied Biosystems Inc., Foster City, CA, USA). The sequencing process was separated in two sets of mix reactions per primer including one for genomic regions of difficult hybridization by the designed sequencing primers (Reaction Mix A) and other for regions of easy hybridization (Reaction Mix B) and performed under the following final concentration conditions: Reaction Mix A (BigDye ${ }^{\mathrm{TM}}$ Sequencing Buffer $(0.75 \times)$ ), $2 \mu \mathrm{L}$ of BigDye ${ }^{\mathrm{TM}}$ Terminator 3.1 Reaction Mix, 
$1 \mu \mathrm{L}$ of primers ( $5 \mu \mathrm{M}$ stock solution) RV4, FW6, and RV9 separately per reaction, $1 \mu \mathrm{L}$ of purified template cDNA, and RNase-Free water to make up a reaction volume of $20 \mu \mathrm{L}$ ) and Reaction Mix B (BigDye $^{\mathrm{TM}}$ Sequencing Buffer $(0.75 \times), 1 \mu \mathrm{L}$ of BigDye ${ }^{\mathrm{TM}}$ Terminator 3.1 Reaction Mix, $1 \mu \mathrm{L}$ of primers (5 $\mu \mathrm{M}$ stock solution) RV2PCR, FW1, FW4, FW5, RV6, 1bRV7, and 1aFW8, separately per reaction, $1 \mu \mathrm{L}$ of purified template cDNA, and RNase-Free water to make up a reaction volume of $10 \mu \mathrm{L}$ ). Cycling conditions included a denaturation step at $96^{\circ} \mathrm{C}$ for $5 \mathrm{~min}, 35$ cycles of $5 \mathrm{~s}$ at $94{ }^{\circ} \mathrm{C}, 10 \mathrm{~s}$ at $50{ }^{\circ} \mathrm{C}$, and $4 \mathrm{~min}$ at $60{ }^{\circ} \mathrm{C}$, which are followed by a cooldown to $4{ }^{\circ} \mathrm{C}$. A purification of the sequencing reaction products was needed before running on the sequencing equipment and nucleotide sequence chromatograms for each sample were obtained.

The primers nucleotide sequences for each sample were joined in a single contig and edited using ChromasPro ${ }^{\circledR}$ software v1.7.6. (Technelysium Pty Ltd., Brisbane, Australia). Finally, complete nucleotide sequences were converted to FASTA format and analyzed online in Geno2pheno (HCV) v0.92 (Saarbrücken, Germany), which provides the baseline resistance analysis profile for each patient. All sequences obtained in this study were submitted to the REGA HCV database from KU LEUVEN.

\subsection{Statistical Analysis}

Statistical analysis was carried out using IBM ${ }^{\circledR}$ SPSS $^{\circledR}$ Statistics v19 (SPSS Inc., Chicago, IL, USA) and Microsoft Excel (v12.0, Microsoft, Redmond, WA, USA). The association between the presence of NS5 RASs and categorical variables was analyzed through a qui-square test with $p$-values below $\alpha=0.05$, which indicates statistical significance.

\section{Results}

\subsection{Statistical Analysis}

Using a confidence level of $95 \%$, statistical analysis indicated that treatment failure was not significantly associated with either the class of NS5 RASs $(p=0.549)$ or the mere non-discriminatory presence of baseline NS5 RASs $(p=0.232)$. However, a statistically significant association was found between treatment failure and the presence of specific baseline NS5 RASs known as Y93C/H $(p=0.04)$ in two out of three recurrent patients.

An additional association between the presence of baseline NS5 RASs and HCV genotype was granted in order to find a connection to other relevant variables that are common in the clinical practice of HCV-infection besides treatment failure. Overall, HCV genotype revealed a strong statistically significant association to the non-discriminatory presence of baseline NS5 RASs $(p=0.001)$ with GT1b being the strongest predictor of this association as well as to the class of NS5 RASs $(p<0.001)$ where GT1b and NS5B RASs were the strongest predictors of association. Moreover, the HCV genotype also exhibited a statistically significant association to the presence of specific baseline NS5 RASs known as A92E/T ( $p=0.007), \mathrm{L} 159 \mathrm{~F}(p<0.001), \mathrm{C} 316 \mathrm{~N}(p<0.001)$, and C451I/Y $(p=0.007)$. GT1b is the strongest predictor of these associations.

\subsection{Prevalence of NS5 RASs and Treatment Outcome}

Among all genotype 1 infected patients, 38.3\% (31/81) presented NS5 RASs at baseline with NS5A class RASs showing the highest prevalence. NS5B RASs and the combined NS5A + NS5B RASs followed in the following percentages: $23.5 \%$ (19/81), 9.9\% (8/81) and 4.9\% (4/81), respectively (see Figure 2). However, the prevalence of NS5A and NS5B RASs would rise up to $28.3 \%(23 / 81)$ and $14.8 \%(12 / 81)$, respectively, when not considering separately the dual-class RASs. Additionally, of the 31 GT1 HCV-infected patients whom presented NS5 RASs at baseline, approximately 58\% (18/31) were co-infected with $\mathrm{HIV} / \mathrm{HCV}$ and disregarded HBV infections. 


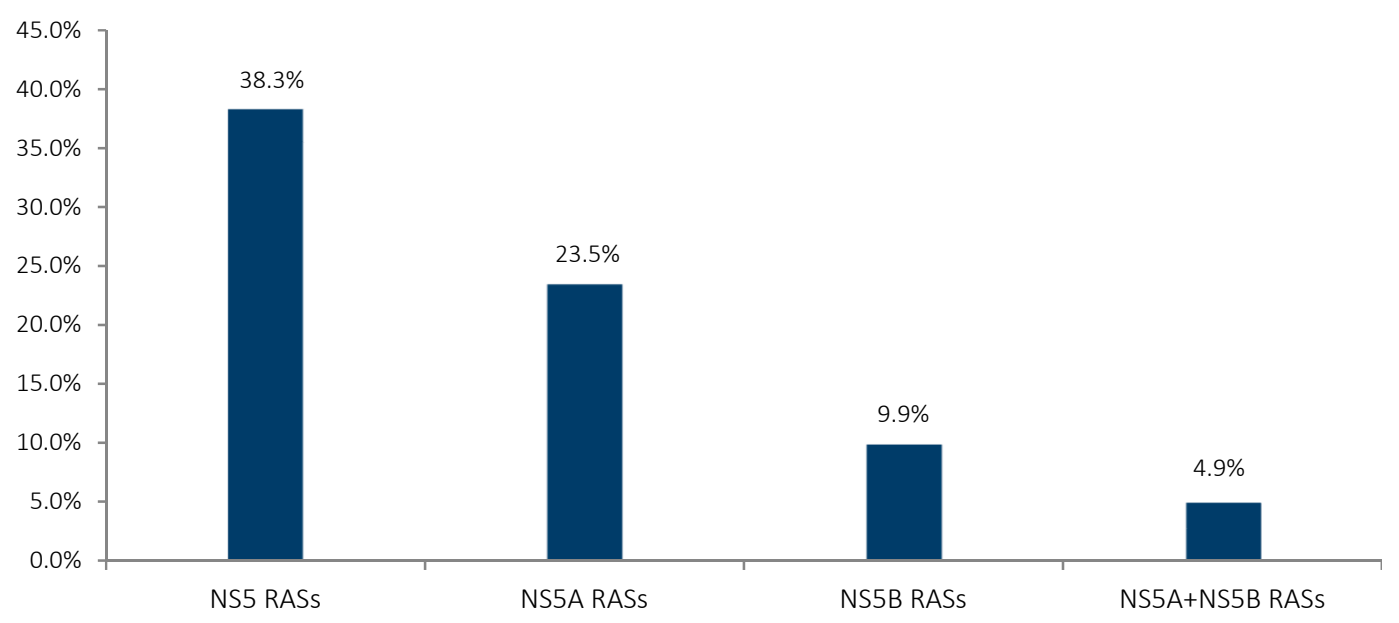

Figure 2. Baseline prevalence of NS5 RASs in all GT1 HCV-infected patients. Substitution analyses were conducted on Sanger sequencing data with a 15\% cut-off limit. Dual-class RASs are assigned as $N S 5 A+N S 5 B$ RASs.

Approximately $27 \%(15 / 56)$ of the GT1a infected patients presented NS5 RASs, which was compared to a much higher percentage of NS5 RASs in the GT1b-infected patients that accounted for $64 \%(16 / 25)$ with NS5B RASs prevailing at 32\% (8/25) followed by NS5A and dual-class RASs both at $16 \%(4 / 25)$ (see Figure 3). However, from another point of view, the GT1b patients showed a higher prevalence of NS5A RASs than for GT1a, namely 32\% (8/25), when not considering separately the dual-class RASs.

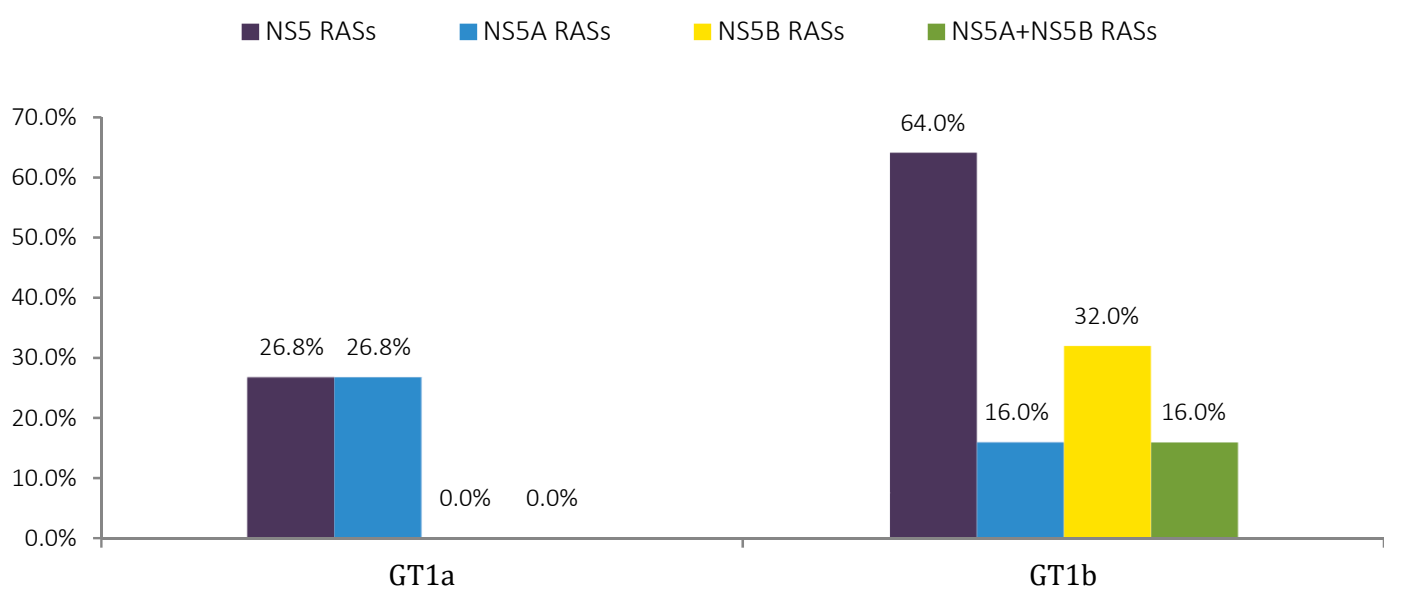

Figure 3. Percentage of HCV-infected patients with NS5 RASs, according to subtype. Substitution analyses were conducted on Sanger sequencing data with a $15 \%$ cut-off limit. Dual-class RASs are assigned as NS5A + NS5B RASs.

Approximately $20 \%(16 / 81)$ of all 81 GT1 infected patients showed at least one RAS that conferred more than 100-fold resistance to ledipasvir (Q30H/R, L31M, and/or Y93C/H) including $21.4 \%(12 / 56)$ and 16\% (4/25) of GT1a and GT1b infected patients, respectively. Moreover, dual-class RASs were only observed in 4 GT1b infected patients while combined intra-class RASs were detected in four GT1a patients concerning the NS5A region $(\mathrm{Q} 30 \mathrm{H}+\mathrm{Y} 93 \mathrm{H})$ and afterward in one and six $\mathrm{GT} 1 \mathrm{~b}$ patients for NS5A (A92T + Y93H) and NS5B (L159F + C316N and L159F + C316N + C451Y) genes, respectively.

Baseline resistance testing of the NS5 coding region showed that the efficacy of SOF and NS5A inhibitors, mainly LDV, was not compromised in most patients who showed a natural presence of RASs before treatment initiation since NS5 RASs were present in $38.2 \%$ of patients who achieved an 
SVR with $22.4 \%$ (17/76), 10.5\% (8/76), and 5.3\% (4/76) corresponding to NS5A, NS5B, and dual-class RASs, respectively (see Figure 4).

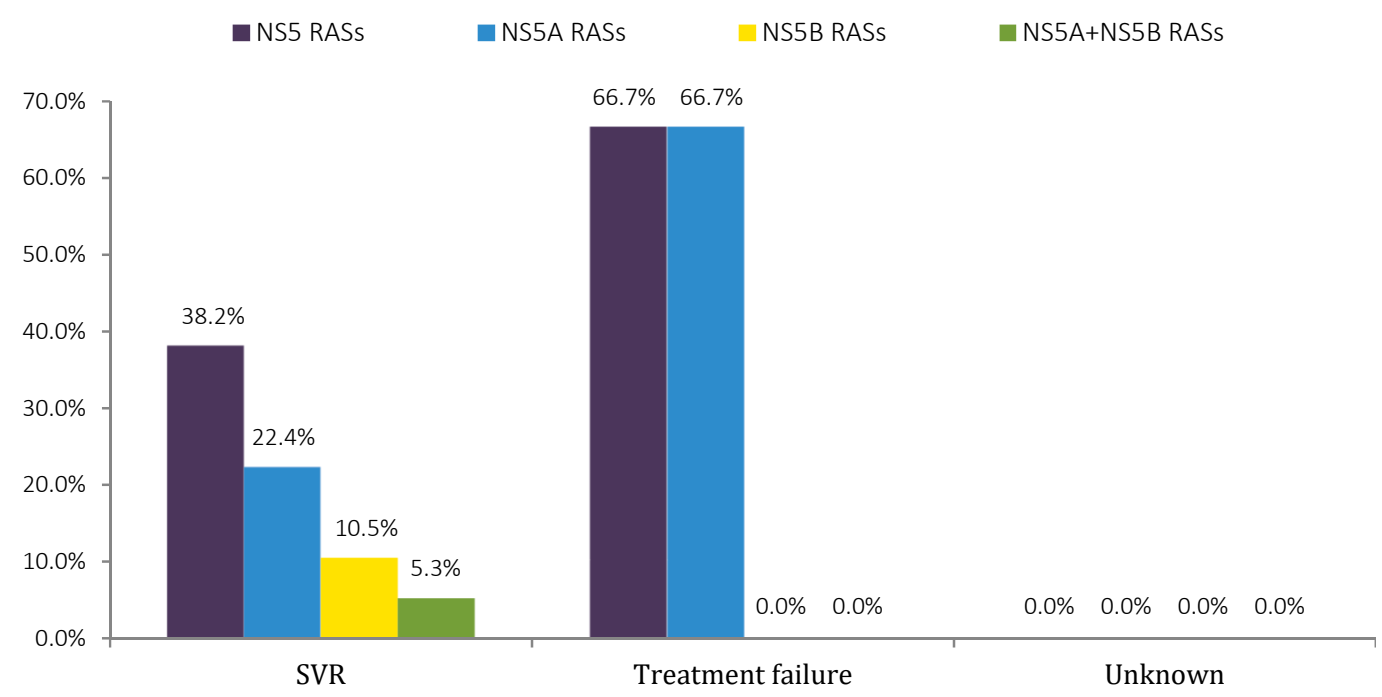

Figure 4. Percentage of HCV infected patients with NS5 RASs, according to treatment outcome status. Substitution analyses were conducted on Sanger sequencing data with a $15 \%$ cut-off limit. Dual-class RASs are assigned as NS5A + NS5B RASs.

Nonetheless, $66.7 \%(2 / 3)$ of the relapsing patients presented NS5A class only RASs, as the combined $\mathrm{Q} 30 \mathrm{H}+\mathrm{Y} 93 \mathrm{H}$ mutations which caused high level resistance to all NS5A inhibitors were detected at baseline in one HIV/HCV GT1a co-infected patient who later failed a treatment with SOF + LDV for 12 weeks. However, another relapsing HIV/HCV GT1a co-infected patient who also failed the same therapeutic settings previously described showed no NS5 RASs at baseline. Furthermore, an isolated $\mathrm{Y} 93 \mathrm{H}$ mutation was also detected at baseline in one GT1b mono-infected patient experiencing virological relapse.

Even though the $\mathrm{Y} 93 \mathrm{H}$ mutation showed a significant effect on treatment outcome $(p=0.04)$ being detected as a dominant substitution for the two patients who did not achieve SVR12 with NS5A RASs, most patients with at least one NS5A RAS conferring $>100$-fold resistance to ledipasvir still achieved SVR12. Moreover, no RASs were detected in the two GT1a infected patients with an unknown treatment outcome.

Overall, 93.5\% (29/31) of patients with baseline NS5 RASs achieved SVR12 of which $54.8 \%$ (17/31), $25.8 \%(8 / 31)$, and $12.9 \%$ (4/31) corresponded to NS5A, NS5B, and NS5A + NS5B class RASs, respectively, when compared to only two patients $(6.5 \%)$ who experienced virological failure carrying NS5A RASs.

\subsection{Prevalence of NS5A Specific RASs}

Major NS5A RASs were detected in 23.2\% (13/56) of GT1a infected patients (M28V, Q30H/R, $\mathrm{L} 31 \mathrm{M}$, and/or $\mathrm{Y} 93 \mathrm{C} / \mathrm{H})$ and in $16 \%(4 / 25)$ of GT1b-infected patients (L31M and $\mathrm{Y} 93 \mathrm{H})$. Yet minor NS5A RASs were also detected in 3.6\% (2/56) of GT1a patients (H58C/P) and in $20 \%(5 / 25)$ of GT1b patients (L28M, H58S, and A92E/T).

The most commonly detected NS5A RAS was Y93C/H with a baseline prevalence of $9.9 \%(8 / 81)$ in all GT1 infected patients, which was followed by L31M and Q30H/R with a prevalence of $8.6 \%$ $(7 / 81)$ and $6.2 \%(5 / 81)$, respectively (see Figure 5). Moreover, $\mathrm{Y} 93 \mathrm{C} / \mathrm{H}$ showed a higher prevalence in GT1b patients than in GT1a with percentages of $12 \%(3 / 25)$ vs. 8.9\% (5/56), respectively. The baseline Y93C/H mutation largely accounted for $25.8 \%(8 / 31)$ of all patients carrying RASs and was followed by $\mathrm{L} 31 \mathrm{M}$ and $\mathrm{Q} 30 \mathrm{H} / \mathrm{R}$ with percentages of $22.6 \%(7 / 31)$ and $16.1 \%(5 / 31)$, respectively. 


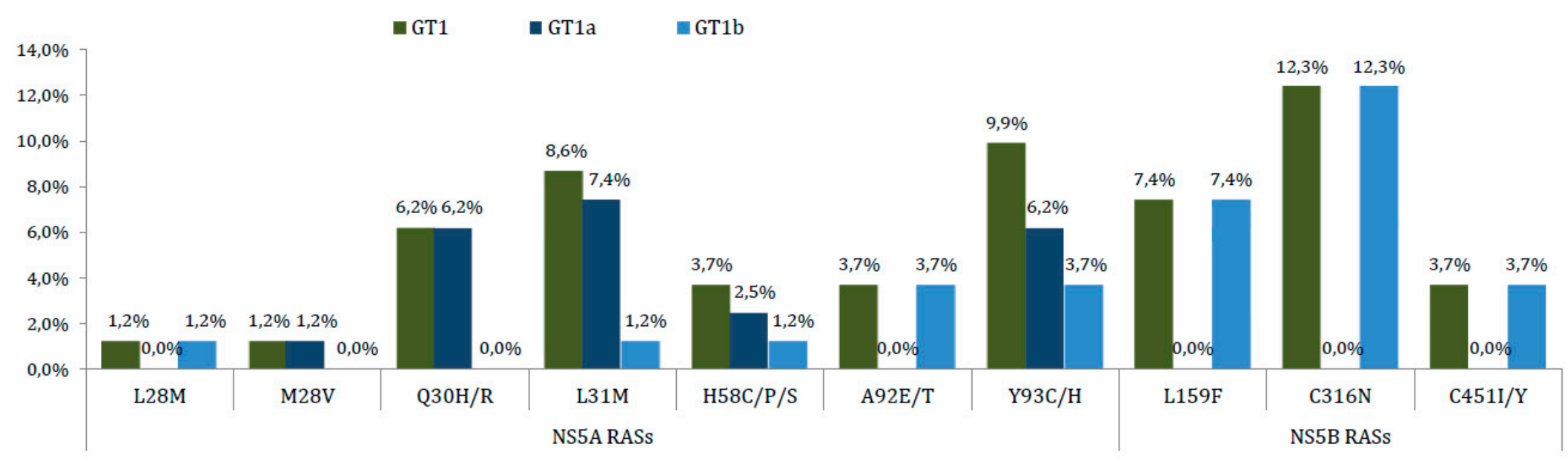

Figure 5. Baseline prevalence of specific NS5 RASs in all 81 HCV-infected patients by HCV subtype. Substitution analyses were conducted on Sanger sequencing data with a $15 \%$ cut-off limit. Dual-class RASs are assigned as NS5A + NS5B RASs. 


\subsection{Prevalence of NS5B Specific RASs}

NS5B RASs accounted for $14.8 \%(12 / 81)$ of GT1 HCV-infected patients when not considering separately the dual-class RASs and were only detected in GT1b patients with all achieving SVR12. Furthermore, these were mainly represented by the C316N mutation, which accounted for $40 \%(10 / 25)$ of GT1b-infected patients and showed the highest prevalence among all patients with baseline NS5 RASs with a percentage of $32.3 \%$ (10/31). The major S282T mutation causing a high level resistance to sofosbuvir was never detected. However, the baseline L159F RAS that confers a reduced susceptibility to this drug was detected in $24 \%(6 / 25)$ of GT1b-infected patients and in $19.4 \%(6 / 31)$ of all patients carrying NS5 RASs.

\section{Discussion}

HCV sequencing is constantly improving and becoming more widely available for selecting optimal therapy especially in difficult-to-treat patients. In summary, baseline resistance analysis has been shown to be quite useful in selecting increasingly specific regimens for each patient and it helps to achieve a complete viral suppression with high SVR rates countering the progression of the virus in patients with persistent viral loads as well as preventing future therapeutic failures associated with unnecessary high-cost salvage DAAs [25]. Overall, NS5A constitutes the most important genomic region considered for the screening of associated RASs. In two studies comparing the effect of baseline NS5A RASs on a SOF + LDV based regimen $[27,28]$, the authors found a higher prevalence of baseline RASs for GT1b than for GT1a with percentages of $25 \%$ (52/206) and $17.6 \%(25 / 142)$ vs. $13 \%(40 / 303)$ and $7.1 \%(12 / 170)$ for each study respectively, but it is still insignificant on SVR rates except for treatment-experienced patients with decompensated cirrhosis infected with GT1a HCV in which these RASs conferred a high fold resistance $(>100)$. More recent data from phase II/III studies of 2108 GT1 infected patients evaluating the effects of baseline NS3, NS5A, and NS5B RASs on the response to a SOF + LDV based regimen, showed that up to $16 \%(338 / 2108)$ and $2.5 \%(43 / 1692)$ of patients had detectable NS5A and NS5B RASs, respectively [29]. This data is further supported from a deep sequencing analysis of baseline NS5A RASs in 276 GT1 infected patients, which shows a prevalence of $21 \%(59 / 276)$ of high level NS5A RASs conferring resistance to ledipasvir [30]. However, a contemporary study described a much lower prevalence with $11.5 \%(102 / 887)$ of treatment-naive GT1 infected patients showing at least one RAS that conferred $>100$-fold resistance to ledipasvir [29]. Along these lines, all regimens based in NS5A inhibitors should include a NI with a high genetic barrier to resistance, currently sofosbuvir, since this combination has been shown to elicit a profound viral suppression $[31,32]$ as well as higher SVR rates when treatment duration is extended to 24 weeks with or without ribavirin. An analysis of 2108 GT1-infected patients who received a regimen of SOF + LDV demonstrated that the reduction in SVR rates appeared to be driven predominantly by patients with NS5A RASs, and $\mathrm{Y} 93 \mathrm{H}$ was detected as a dominant substitution [29]. Furthermore, another study based on deep sequencing analysis of baseline NS5A RASs in 276 and 32 patients infected with GT1 and GT4 HCV, respectively, showed that all patients who failed to achieve SVR12 presented at least one NS5A RAS (M28T, Q30H/K/R, L31M/V, and/or Y93C/H) [30].

Regarding NS5A specific RASs, a 2015 analysis of more than 3000 GT1 NS5A sequences has demonstrated a higher baseline prevalence of the $\mathrm{Y} 93 \mathrm{C} / \mathrm{H} / \mathrm{N}$ mutation especially in GT1b, which was mostly found in South Korea (15.3\%) followed by Japan (13.9\%) and Spain (13.6\%) while, in GT1a, the baseline Q30E/H/R mutation was described as the most commonly detected. The highest prevalence was found in Italy $(4.9 \%)$, which was followed by France $(4.8 \%)$ and New Zealand $(3.9 \%)$ [33]. Moreover, an analysis from the same year of NS5A sequences in 132 Japanese GT1b HCV-infected patients established that baseline NS5A RASs are common in treatment-naive patients infected with GT1b, which demonstrates an even higher prevalence of the $\mathrm{Y} 93 \mathrm{H}$ mutation with a percentage of $25 \%$ (32/132) [34].

With regard to the NS5B coding region, patients treated with regimens based on NS5B polymerase inhibitors, particularly NIs, tend to exhibit a low prevalence of baseline RASs [24], but when 
detected, the most frequently encountered appear to be L159F, C316N/Y, L320F, V321A, M414T, and S556G [33,35-45]. Dasabuvir, however, possesses a low genetic barrier to resistance since the associated $\mathrm{C} 316 \mathrm{~N}$ mutation tends to achieve a substantial baseline prevalence of $10 \%$ to $36 \%$ in GT1b-infected patients [35,46-48]. Moreover, an analysis of more than 7800 NS5A and NS5B sequences from $\mathrm{HCV}$-infected patients across 22 countries showed a prevalence of up to 34\% for the L159F mutation in GT1b infected patients [33]. Several studies analyzing the natural presence of NS5B RASs equally refute an associated significant impact on SVR12 rates [49,50], which further strengthens this study's data.

In conclusion, the obtained data supports the usefulness of resistance testing prior to treatment initiation, which prevents relapses associated with the presence of baseline RASs. A statistically significant association was found between treatment failure and the baseline presence of specific NS5 RASs known as $\mathrm{Y93C} / \mathrm{H}(p=0.04)$. With this in mind, an interesting recommendation to take into account would be to implement a protocol of baseline resistance testing directed only for the clinically-relevant Y93 amino acid position of the NS5A gene since all other NS5 RASs, excluding the rare $\mathrm{S} 282 \mathrm{~T}$ mutation which was not detected, do not seem to have a significant impact on a SOF/LDV based treatment. However, this reduced sampling can constitute a limiting factor since it may underestimate statistical analysis results and lead to overall higher RASs rates when compared to previous studies [24,29,33-35,37,43,50-53]. Furthermore, additional clinical features of the enrolled patients such as RBV use, regimen's length, fibrosis stage, and degree of portal hypertension were unavailable at the time of this study and response rates over these parameters were unobtainable. These factors are predictors of failure and could have very well enhanced the role of baseline RASs in response to treatment. Along these lines, baseline NS5 RASs seem to have minimal effects on patient responses to sofosbuvir plus NS5A inhibitors (LDV, DCV, VEL) based therapies. It is well established through cumulative research data that, when baseline NS5A RASs in particular do have effects, they could be largely overcome by extending treatment duration and/or through treatment intensification with the addition of RBV, which drastically reduced the impact of NS5A baseline RASs [25,49,54-56]. Additionally, the cost-effectiveness of baseline resistance testing was accessed in a recent paper describing how the inquiry of baseline NS5A RASs prior to treatment with EBR/GZR is a cost-effective measure resulting in more QALYs (quality-adjusted life years) among GT1a treatment-naive or treatment-experienced patients when compared to a treatment with EBR/GZR without baseline resistance testing. LDV/SOF or 3D based regimens are, therefore, another factor in favor of baseline resistance testing prior to treatment initiation [57].

Lastly, the importance of total adherence to the treatment should always be encouraged and insisted upon in an elucidative way by physicians in order to prevent potential relapses in patients since lack of adherence to treatment is perhaps the main cause of RASs-related treatment failure.

Supplementary Materials: The following are available online at http:/ /www.mdpi.com/1999-4915/10/5/223/s1, Table S1: Primers for RT-PCR/cDNA synthesis (outer PCR), nested PCR (inner PCR), and sequencing of HCV NS5 coding region.

Author Contributions: R.B. performed the experiments, analyzed the data, and wrote the paper. R.M. conceived and designed the experiments and wrote the paper. F.G. performed the experiments and analyzed the sequencing data. I.D., A.C., J.C., and I.C. contributed to the procedures and wrote the paper. P.B., F.V., A.M., and K.M. contributed to the patients data and treatment regimens information. P.G. contributed to patients' data, analyzed the sequencing data, and wrote the paper.

Funding: This research received no external funding.

Acknowledgments: I would first like to thank my tutor Professor Perpetua Gomes for granting me the opportunity to pursue my master's thesis at the Clinical Microbiology and Molecular Biology Laboratory of Egas Moniz Hospital (CHLO). Regarding my work per se, I couldn't have succeeded without the help of my team co-workers at the Molecular Biology department who tutored and taught me laboratory processes by always making themselves available to pass along some of their hardworking experience. This project wouldn't have been possible without Rute Marcelino (Medical Microbiology Department, IHMT, Lisbon) whose vital contributions were the groundbreaking keys to this thesis. Lastly, I would like to acknowledge the involved physicians of the Department of Infectious Diseases of Egas Moniz Hospital for their availability and data granted throughout this 
project. This research project was funded by the master's tuitions of the corresponding author and public funds from Egas Moniz Hospital (CHLO).

Conflicts of Interest: The authors declare no conflict of interest.

\section{References}

1. Abajobir, A.A.; Abate, K.H.; Abbafati, C. Global, regional, and national incidence, prevalence, and years lived with disability for 328 diseases and injuries for 195 countries, 1990-2016: A systematic analysis for the Global Burden of Disease Study 2016. Lancet 2017, 390, 1211-1259. [CrossRef]

2. Abajobir, A.A.; Abbafati, C.; Abbas, K.M. Global, regional, and national age-sex specific mortality for 264 causes of death, 1980-2016: A systematic analysis for the Global Burden of Disease Study 2016. Lancet 2017, 390, 1151-1210. [CrossRef]

3. Institute for Health Metrics and Evaluation (IHME). GBD Results Tool. Global Health Data Exchange (GHDx). Available online: http:/ /ghdx.healthdata.org/gbd-results-tool (accessed on 19 October 2017).

4. Messina, J.P.; Humphreys, I.; Flaxman, A. Global distribution and prevalence of Hepatitis C virus genotypes. Hepatology 2015, 61, 77-87. [CrossRef] [PubMed]

5. Zeuzem, S.; Andreone, P.; Pol, S.; Lawitz, E.; Diago, M.; Roberts, S.; Focaccia, R.; Younossi, Z.; Foster, G.R.; Horban, A.; et al. Telaprevir for retreatment of HCV infection. N. Engl. J. Med. 2011, 364, 2417-2428. [CrossRef] [PubMed]

6. Jacobson, I.M.; Dore, G.J.; Foster, G.R.; Fried, M.W.; Radu, M.; Rafalsky, V.V.; Moroz, L.; Craxi, A.; Peeters, M.; Lenz, O.; et al. Simeprevir with pegylated interferon alfa 2a plus ribavirin in treatment-naive patients with chronic Hepatitis C virus genotype 1 infection (QUEST-1): A phase 3, randomised, double-blind, placebo-controlled trial. Lancet 2014, 384, 403-413. [CrossRef]

7. Lawitz, E.; Mangia, A.; Wyles, D.; Rodriguez-Torres, M.; Hassanein, T.; Gordon, S.C.; Schultz, M.; Davis, M.N.; Kayali, Z.; Reddy, K.R.; et al. Sofosbuvir for Previously Untreated Chronic Hepatitis C Infection. N. Engl. J. Med. 2013, 368, 1878-1887. [CrossRef] [PubMed]

8. Sullivan, J.C.; de Meyer, S.; Bartels, D.J.; Dierynck, I.; Zhang, E.Z.; Spanks, J.; Tigges, A.M.; Ghys, A.; Dorrian, J.; Adda, N.; et al. Evolution of treatment-emergent resistant variants in telaprevir phase 3 clinical trials. Clin. Infect. Dis. 2013, 57, 221-229. [CrossRef] [PubMed]

9. Nelson, D.R.; Cooper, J.N.; Lalezari, J.P.; Lawitz, E.; Pockros, P.J.; Gitlin, N.; Freilich, B.F.; Younes, Z.H.; Harlan, W.; Ghalib, R.; et al. All-oral 12-week treatment with daclatasvir plus sofosbuvir in patients with Hepatitis C virus genotype 3 infection: ALLY-3 phase III study. Hepatology 2015, 61, 1127-1135. [CrossRef] [PubMed]

10. Zeuzem, S.; Ghalib, R.; Reddy, K.R.; Pockros, P.J.; Ari, Z.B.; Zhao, Y.; Brown, D.D.; Wan, S.; DiNubile, M.J.; Nguyen, B.Y.; et al. Grazoprevir-Elbasvir combination therapy for treatment-naive cirrhotic and noncirrhotic patients with chronic Hepatitis C virus genotype 1, 4, or 6 infection: A randomized trial. Ann. Intern. Med. 2015, 163, 1-13. [CrossRef] [PubMed]

11. Soriano, V.; Vispo, E.; de Mendoza, C.; Labarga, P.; Fernandez-Montero, J.V.; Poveda, E.; Treviño, A.; Barreiro, P. Hepatitis C therapy with HCV NS5B polymerase inhibitors. Expert Opin. Pharmacother. 2013, 14, 1161-1170. [CrossRef] [PubMed]

12. Wu, S.; Kanda, T.; Nakamoto, S.; Imazeki, F.; Yokosuka, O. Hepatitis C virus protease inhibitor-resistance mutations: Our experience and review. World J. Gastroenterol. 2013, 19, 8940-8948. [CrossRef] [PubMed]

13. Nakamoto, S.; Kanda, T.; Wu, S.; Shirasawa, H.; Yokosuka, O. Hepatitis C virus NS5A inhibitors and drug resistance mutations. World J. Gastroenterol. 2014, 20, 2902-2912. [CrossRef] [PubMed]

14. European Association for the Study of the Liver (EASL). EASL recommendations on treatment of Hepatitis C 2016. J. Hepatol. 2016, 61, 373-395. [CrossRef]

15. Afdhal, N.; Reddy, K.R.; Nelson, D.R.; Lawitz, E.; Gordon, S.C.; Schiff, E.; Nahass, R.; Ghalib, R.; Gitlin, N.; Herring, R.; et al. Ledipasvir and sofosbuvir for previously treated HCV genotype 1 infection. N. Engl. J. Med. 2014, 370, 1483-1493. [CrossRef] [PubMed]

16. Afdhal, N.; Zeuzem, S.; Kwo, P.; Chojkier, M.; Gitlin, N.; Puoti, M.; Romero-Gomez, M.; Zarski, J.P.; Agarwal, K.; Buggisch, P.; et al. Ledipasvir and Sofosbuvir for Untreated HCV Genotype 1 Infection. N. Engl. J. Med. 2014, 370, 1889-1898. [CrossRef] [PubMed] 
17. Kowdley, K.V.; Gordon, S.C.; Reddy, K.R.; Rossaro, L.; Bernstein, D.E.; Lawitz, E.; Shiffman, M.L.; Schiff, E.; Ghalib, R.; Ryan, M.; et al. Ledipasvir and Sofosbuvir for 8 or 12 Weeks for Chronic HCV without Cirrhosis. N. Engl. J. Med. 2014, 370, 1879-1888. [CrossRef] [PubMed]

18. Bourlière, M.; Bronowicki, J.P.; De Ledinghen, V.; Hézode, C.; Zoulim, F.; Mathurin, P.; Tran, A.; Larrey, D.G.; Ratziu, V.; Alric, L.; et al. Ledipasvir-sofosbuvir with or without ribavirin to treat patients with $\mathrm{HCV}$ genotype 1 infection and cirrhosis non-responsive to previous protease-inhibitor therapy: A randomised, double-blind, phase 2 trial (SIRIUS). Lancet Infect. Dis. 2015, 15, 397-404. [CrossRef]

19. Bourliere, M.; Bronowicki, J. Ledipasvir/sofosbuvir fixed dose combination is safe and efficacious in cirrhotic patients who have previously failed protease-inhibitor based triple therapy. In Proceedings of the 65th AASLD Meeting, Boston, MA, USA, 7-11 November 2014.

20. Curry, M.; Modi, A.A.; Pungpapong, S.; Leise, M.; Aqel, B.; LLewellyn, J.; Williams, L.A.; Natha, M.; Brainard, D.M.; Kreter, B.; et al. Real World Effectiveness of Ledipasvir/Sofosbuvir in Treatment-Experienced Cirrhotic Genotype 1 Patients with Chronic HCV: A Comparative Analysis of Gilead Sponsored Trials with 4 Real-World Cohorts. J. Hepatol. 2016, 64, S631-S832. [CrossRef]

21. Sarrazin, C.; Zeuzem, S. Resistance to Direct Antiviral Agents in Patients with Hepatitis C Virus Infection. Gastroenterology 2010, 138, 447-462. [CrossRef] [PubMed]

22. Park, Y.; Ahn, S.J.; Kim, S.S.; Cheong, J.Y.; Cho, S.W. Baseline and Post-baseline Resistance Analyses of Phase 2/3 Studies of Ledipasvir/Sofosbuvir \pm RBV. Hepatology 2014, 60, 1128.

23. Susser, S.; Dietz, J.; Vermehren, J.; Peiffer, K.H.; Passmann, S.; Perner, D.; Berkowski, C.; Ferenci, P.; Buti, M.; Müllhaupt, B.; et al. European RAVs Database: Frequency and Characteristics of RAVs in treatment-naive and DAA-experienced patients. In Proceedings of the International Liver Congress (EASL), Barcelona, Spain, 13-17 April 2016.

24. Chen, Z.-W.; Li, H.; Ren, H.; Hu, P. Global prevalence of pre-existing HCV variants resistant to direct-acting antiviral agents (DAAs): Mining the GenBank HCV genome data. Sci. Rep. 2016, 6, 20310. [CrossRef] [PubMed]

25. Sarrazin, C. The importance of resistance to direct antiviral drugs in HCV infection in clinical practice. J. Hepatol. 2016, 64, 486-504. [CrossRef] [PubMed]

26. Dvory-Sobol, H.; Doehle, B.; Svarovskaia, E.; McCarville, J.F.; Pang, P.; Afdhal, N.; Kowdley, K.V.; McHutchison, J.; Miller, M.; Mo, H. The Prevalence of HCV NS5A, Nucleoside and Protease Inhibitor Resistance Associated Variants and the Effects on Treatment with Ledipasvir/Sofosbuvir \pm RBV in the Phase 3 ION Studies. In Proceedings of the International Workshop on Antiviral Drug Resistance, Berlin, Germany, 3-7 June 2014.

27. Sarrazin, C.; Dvory-Sobol, H.; Svarovskaia, E.S. The Prevalence and the Effect of HCV NS5A Resistance-Associated Variants in Patients with Compensated Cirrhosis Treated with Ledipasvir/Sofosbuvir \pm RBV. In Proceedings of the 50th Annual Meeting of the European Association for the Study of the Liver, Vienna, Austria, 22-26 April 2015.

28. Dietz, J.; Susser, S.; Berkowski, C.; Perner, D.; Zeuzem, S.; Sarrazin, C. Consideration of viral resistance for optimization of direct antiviral therapy of Hepatitis C virus genotype 1-infected patients. PLoS ONE 2015, 10, e0134395. [CrossRef] [PubMed]

29. Manns, M.; Samuel, D.; Gane, E.J.; Mutimer, D.; McCaughan, G.; Buti, M.; Prieto, M.; Calleja, J.L.; Peck-Radosavljevic, M.; Müllhaupt, B.; et al. Ledipasvir and sofosbuvir plus ribavirin in patients with genotype 1 or 4 Hepatitis C virus infection and advanced liver disease: A multicentre, open-label, randomised, phase 2 trial. Lancet Infect. Dis. 2016, 16, 685-697. [CrossRef]

30. Sarrazin, C.; Dvory-Sobol, H.; Svarovskaia, E.S.; Doehle, B.P.; Pang, P.S.; Chuang, S.M.; Ma, J.; Ding, X.; Afdhal, N.H.; Kowdley, K.V.; et al. Prevalence of Resistance-Associated Substitutions in HCV NS5A, NS5B, or NS3 and Outcomes of Treatment With Ledipasvir and Sofosbuvir. Gastroenterology 2016, 151, 501-512. [CrossRef] [PubMed]

31. Lawitz, E.J.; Gruener, D.; Hill, J.M.; Marbury, T.; Moorehead, L.; Mathias, A.; Cheng, G.; Link, J.O.; Wong, K.A.; Mo, H.; et al. A phase 1, randomized, placebo-controlled, 3-day, dose-ranging study of GS-5885, an NS5A inhibitor, in patients with genotype 1 Hepatitis, C. J. Hepatol. 2012, 57, 24-31. [CrossRef] [PubMed]

32. Gao, M.; Nettles, R.E.; Belema, M.; Snyder, L.B.; Nguyen, V.N.; Fridell, R.A.; Serrano-Wu, M.H.; Langley, D.R.; Sun, J.H.; O'Boyle, D.R.; et al. Chemical genetics strategy identifies an HCV NS5A inhibitor with a potent clinical effect. Nature 2010, 465, 96-100. [CrossRef] [PubMed] 
33. Svarovskaia, E.S.; Zeuzem, S.; Hedskog, C. Prevalence of Pretreatment NS5A and NS5B Resistance-Associated Variants and Genetic Variation within HCV Subtypes Across Different Countries/Gilead-Study. In Proceedings of the 50th Annual Meeting of the European Association for the Study of the Liver, Vienna, Austria, 22-26 April 2015.

34. Hirotsu, Y.; Kanda, T.; Matsumura, H.; Moriyama, M.; Yokosuka, O.; Omata, M. HCV NS5A resistance-associated variants in a group of real-world Japanese patients chronically infected with HCV genotype 1b. Hepatol. Int. 2015, 9, 424-430. [CrossRef] [PubMed]

35. Di Maio, V.C.; Cento, V.; Mirabelli, C.; Artese, A.; Costa, G.; Alcaro, S.; Perno, C.F.; Ceccherini-Silberstein, F. Hepatitis C virus genetic variability and the presence of NS5B resistance-Associated mutations as natural polymorphisms in selected genotypes could affect the response to NS5B inhibitors. Antimicrob. Agents Chemother. 2014, 58, 2781-2797. [CrossRef] [PubMed]

36. Plaza, Z.; Soriano, V.; Vispo, E.; del Mar Gonzalez, M.; Barreiro, P.; Seclén, E.; Poveda, E. Prevalence of natural polymorphisms at the HCV NS5A gene associated with resistance to daclatasvir, an NS5A inhibitor. Antivir. Ther. 2012, 17, 921-926. [CrossRef] [PubMed]

37. Poveda, E.; Wyles, D.L.; Mena, Á.; Pedreira, J.D.; Castro-Iglesias, Á.; Cachay, E. Update on Hepatitis C virus resistance to direct-acting antiviral agents. Antivir. Res. 2014, 108, 181-191. [CrossRef] [PubMed]

38. Bartels, D.J.; Zhou, Y.; Zhang, E.Z.; Marcial, M.; Byrn, R.A.; Pfeiffer, T.; Tigges, A.M.; Adiwijaya, B.S.; Lin, C.; Kwong, A.D.; et al. Natural prevalence of Hepatitis C virus variants with decreased sensitivity to NS3.4A protease inhibitors in treatment-naive subjects. J. Infect. Dis. 2008, 198, 800-807. [CrossRef] [PubMed]

39. Treviño, A.; Parra, P.; Rodríguez, C.; Madejón, A.; Plaza, Z.; Poveda, E.; Soriano, V. Natural polymorphisms associated with resistance to new antivirals against HCV in newly diagnosed HIV-HCV-coinfected patients. Antivir. Ther. 2011, 16, 413-416. [CrossRef] [PubMed]

40. Vallet, S.; Viron, F.; Henquell, C.; Le Guillou-Guillemette, H.; Lagathu, G.; Abravanel, F.; Trimoulet, P.; Soussan, P.; Schvoerer, E.; Rosenberg, A.; et al. NS3 protease polymorphism and natural resistance to protease inhibitors in French patients infected with HCV genotypes 1-5. Antivir. Ther. 2011, 16, 1093-1102. [CrossRef] [PubMed]

41. Vicenti, I.; Rosi, A.; Saladini, F.; Meini, G.; Pippi, F.; Rossetti, B.; Sidella, L.; Di Giambenedetto, S.; Almi, P.; De Luca, A.; et al. Naturally occurring Hepatitis C virus (HCV) NS3/4A protease inhibitor resistance-related mutations in HCV genotype 1-infected subjects in Italy. J. Antimicrob. Chemother. 2012, 67, 984-987. [CrossRef] [PubMed]

42. Tong, X.; Le Pogam, S.; Li, L.; Haines, K.; Piso, K.; Baronas, V.; Yan, J.M.; So, S.S.; Klumpp, K.; Nájera, I. In vivo emergence of a novel mutant $\mathrm{L} 159 \mathrm{~F} / \mathrm{L} 320 \mathrm{~F}$ in the NS5B polymerase confers low-level resistance to the HCV polymerase inhibitors mericitabine and sofosbuvir. J. Infect. Dis. 2014, 209, 668-675. [CrossRef] [PubMed]

43. Childs-Kean, L.M.; Hand, E.O. Simeprevir and sofosbuvir for treatment of chronic Hepatitis C infection. Clin. Ther. 2015, 37, 243-267. [CrossRef] [PubMed]

44. Lam, A.M.; Espiritu, C.; Bansal, S.; Steuer, H.M.; Niu, C.; Zennou, V.; Keilman, M.; Zhu, Y.; Lan, S.; Otto, M.J.; et al. Genotype and subtype profiling of PSI-7977 as a nucleotide inhibitor of Hepatitis C virus. Antimicrob. Agents Chemother. 2012, 56, 3359-3368. [CrossRef] [PubMed]

45. Poordad, F.; Hezode, C.; Trinh, R.; Kowdley, K.V.; Zeuzem, S.; Agarwal, K.; Shiffman, M.L.; Wedemeyer, H.; Berg, T.; Yoshida, E.M.; et al. ABT-450/r-Ombitasvir and Dasabuvir with Ribavirin for Hepatitis C with Cirrhosis. N. Engl. J. Med. 2014, 370, 1973-1982. [CrossRef] [PubMed]

46. Krishnan, P.; Tripathi, R.; Schnell, G.; Reisch, T.; Beyer, J.; Irvin, M.; Xie, W.; Larsen, L.; Pod-sadecki, T.; Pilot-Matias, T.; et al. Pooled analysis of resistance in patients treated with ombitasvir/ABT-450/r and dasabuvir with or without ribavirin in Phase 2 and Phase 3 clinical trials. Hepatology 2014, 60, 1134A-1135A.

47. Kati, W.; Koev, G.; Irvin, M.; Beyer, J.; Liu, Y.; Krishnan, P.; Reisch, T.; Mondal, R.; Wagner, R.; Molla, A.; et al. In vitro activity and resistance profile of dasabuvir, a nonnucleoside Hepatitis $C$ virus polymerase inhibitor. Antimicrob. Agents Chemother. 2015, 59, 1505-1511. [CrossRef] [PubMed]

48. Alves, R.; Queiroz, A.T.; Pessoa, M.G.; da Silva, E.F.; Mazo, D.F.; Carrilho, F.J.; Carvalho-Filho, R.J.; Carvalho, I.M. The presence of resistance mutations to protease and polymerase inhibitors in Hepatitis C virus sequences from the Los Alamos databank. J. Viral Hepat. 2013, 20, 414-421. [CrossRef] [PubMed] 
49. Charlton, M.; Manns, M.; Dvory-Sobol, H.; Svarovskaia, E.; Doehle, B.; Arterburn, S.; Yun, C.; Brainard, D.M.; Mchutchison, J.G.; Miller, M.D.; et al. Resistance Analyses for Ledipasvir/Sofosbuvir-Containing Regimens in patients infected with chronic HCV who have advanced liver disease or are post liver Transplant (SOLAR-1 and -2 Studies). In Proceedings of the International Liver Congress (EASL), Barcelona, Spain, 13-17 April 2016.

50. Watabe, T.; Korenaga, M.; Sugiyama, M.; Kumagai, E.; Ueyama, M.; Aoki, Y.; Yamagiwa, Y.; Korenaga, K.; Imamura, M.; Murata, K.; et al. Distribution of pre-existing NS5A/NS5B resistance associated variants in genotype $1 \mathrm{~B}$ patients with Hepatitis $\mathrm{C}$ virus and response to direct acting antivirals. Hepatology 2015, $62,1083 \mathrm{~A}$.

51. Svarovskaia, E.S.; Gane, E.; Dvory-Sobol, H.; Martin, R.; Doehle, B.; Hedskog, C. L159F and V321A Sofosbuvir Resistance Associated HCV NS5B Substitutions. Infect. Dis. Soc. Am. 2016, 213, 1240-1247. [CrossRef] [PubMed]

52. Zeuzem, S.; Mizokami, M.; Pianko, S.; Mangia, A.; Han, K.H.; Martin, R.; Svarovskaia, E.; Dvory-Sobol, H.; Doehle, B.; Pang, P.S. Prevalence of pre-treatment NS5A resistance associated variants in genotype 1 patients across different regions using deep sequencing and effect on treatment outcome with LDV/SOF. In Proceedings of the AASLD Meeting, San Francisco, CA, USA, 13-17 November 2015.

53. Welzel, T.M.; Bhardwaj, N.; Hedskog, C.; Chodavarapu, K.; Camus, G.; McNally, J.; Brainard, D.; Miller, M.D.; Mo, H.; Svarovskaia, E.; et al. Global Epidemiology of HCV Subtypes and Resistance-associated Substitutions Evaluated by Sequencing-Based Subtype Analyses. J. Hepatol. 2017, 67, 224-236. [CrossRef] [PubMed]

54. Feld, J.J.; Jacobson, I.M.; Hézode, C.; Asselah, T.; Ruane, P.J.; Gruener, N.; Abergel, A.; Mangia, A.; Lai, C.L.; Chan, H.L.; et al. Sofosbuvir and Velpatasvir for HCV Genotype 1, 2, 4, 5, and 6 Infection ASTRAL-1. N. Engl. J. Med. 2015, 373, 2599-2607. [CrossRef] [PubMed]

55. Kwo, P.; Poordad, F.; Porcalla, A.; Gane, E.; Lalezari, J.; Wyles, D.; Liu, R.; Kort, J.; Mensa, F.J. Safety of ABT-493 and ABT-530 co-administered in patients with HCV genotype 1-6 infection: Results from the SURVEYOR-I and SURVEYOR-II studies. Gastroenterology 2016, 150, S1093. [CrossRef]

56. Muir, A.J.; Strasser, S.; Wang, S.; Shafran, S.; Bonacini, M.; Kwo, P.; Wyles, D.; Gane, E.; Lovell, S.S.; Lin, C.W.; et al. High SVR rates with ABT-493 + ABT-530 co-administered for 8 weeks in non-cirrhotic patients with genotype 3 infection. In Proceedings of the International Liver Congress (EASL), Barcelona, Spain, 13-17 April 2016.

57. Elbasha, E.H.; Robertson, M.N.; Nwankwo, C. The cost-effectiveness of testing for NS5a resistance-associated polymorphisms at baseline in genotype 1a-infected (treatment-naïve and treatment-experienced) subjects treated with all-oral elbasvir/grazoprevir regimens in the United States. Aliment. Pharmacol. Ther. 2017, 45, 455-467. [CrossRef] [PubMed]

(C) 2018 by the authors. Licensee MDPI, Basel, Switzerland. This article is an open access article distributed under the terms and conditions of the Creative Commons Attribution (CC BY) license (http://creativecommons.org/licenses/by/4.0/). 